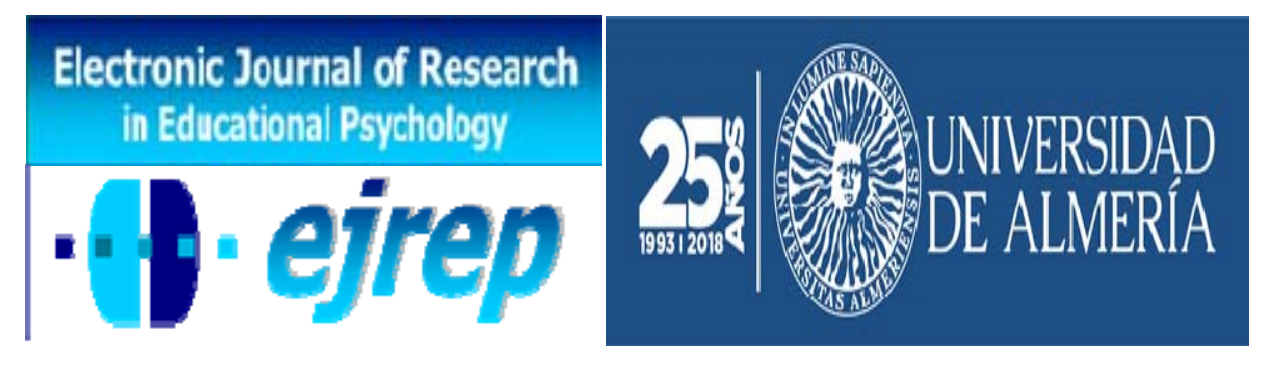

Tllustre Colegio oficial

L dE AMOALUCÍA ORIENTA.

\title{
Análisis de situaciones y perfiles de riesgo respecto al sexismo y la violencia de género en los adolescentes españoles
}

\section{Ana Martínez Dorado ${ }^{1}$, Silvia García Dauder ${ }^{2}$, Lilian Ve- lasco Furlong ${ }^{3}$}

${ }^{1}$ Universidad Rey Juan Carlos, Madrid

${ }^{2}$ Medicina y Cirugía, Psicología, Medicina Preventiva y Salud Pública e Inmunología Microbiología Médica y Enfermería y Estomatología. Área Personalidad, Evaluación y Tratamiento Psicológico. Universidad Rey Juan Carlos,

Madrid

${ }^{3}$ Medicina y Cirugía, Psicología, Medicina Preventiva y Salud Pública e Inmunología Microbiología Médica y Enfermería y Estomatología. Área Psicología

Social. Universidad Rey Juan Carlos, Madrid

\section{España}

Correspondencia: Ana Martínez Dorado. Avenida de la Reina Victoria, $82^{\circ} 28003$, Madrid. España. E-mail: a.martinezdor@alumnos.urjc.es

(C) Universidad de Almería e Ilustre Colegio Oficial de la Psicología de Andalucía Oriental (Spain) 


\section{Resumen}

Introducción. La violencia entre la pareja es una forma de violencia que se produce en todos los estratos y edades de la sociedad. En edades tempranas, como la adolescencia, pueden darse ciertas conductas y creencias que justifiquen la violencia, aparte de poder ser el germen de una violencia futura. Las creencias que tiene este sector de la población sobre las conductas que pudiesen ser de maltrato son muy importantes para poder detectar líneas de actuación y/o prevención. El objetivo de este estudio es evaluar si los adolescentes españoles consideran como tal las conductas de maltrato y en qué gravedad. Además, se considera la percepción que tienen las mujeres y los hombres, no sólo de las conductas de maltrato del hombre a la mujer sino de la mujer hacia el hombre.

Método. La población del estudio son estudiantes de enseñanza secundaria obligatoria y no obligatoria con edades comprendidas entre los 14 y los 22 años. La muestra total es de 874 (430 chicas y 444 chicos). El cuestionario está formado de 15 conductas en torno a las cuales se pregunta si representan maltrato: 14 de las cuales son incluidas como indicadores de la violencia de género en los estudios sobre este tema.

Resultados. Los resultados muestran que los adolescentes españoles identifican las conductas de maltrato como tales (ya sean de chico a chica o de chica a chico), con ciertas excepciones. De forma generalizada, las chicas son más conscientes de las conductas de maltrato. De las 14 conductas descritas, en 8 de ellas existe unanimidad por ambos sexos en considerarlas conductas de maltrato, tanto de hombre hacia la mujer como de mujer a hombre. Sin embargo, muestran una tendencia a puntuar con menor gravedad aquellos ítems que hacen referencia a conductas de maltrato más de tipo emocional que físico. Por último, se obtienen diferencias significativas según la edad, siendo las personas de mayor grupo de edad las que tienen una mayor percepción de las conductas como maltrato.

Discusión y conclusiones. El conjunto de resultados centrales es que tanto chicos como chicas valoran las conductas de maltrato como tal, aunque ambos sexos las valoran como tal, las chicas tienden a hacerlo con una mayor severidad. Lo que sí se observa es una tendencia en las puntuaciones a considerar en mayor grado ciertas conductas cuando es la chica la que lo evalúa. Respecto a que el reconocimiento de la violencia se haga más manifiesto en el grupo de mayor edad se pueden formular diferentes hipótesis no excluyentes.

Palabras-clave. Violencia de género; Adolescencia; Edad; Factores de riesgo; Actitudes y Creencias. 


\begin{abstract}
Introduction. Violence between partners is a form of violence that occurs in all strata and ages of society. At early ages, such as adolescence, certain behaviors and beliefs that justify violence can be given, apart from being the germ of future violence. The beliefs that this sector of the population has about the behaviors that could be of abuse are very important to detect lines of action and / or prevention. The objective of this study is to assess whether Spanish adolescents consider abuse behaviors and how serious they are. In addition, the perception that women and men have is considered, not only of the behaviors of mistreatment of man to woman but of woman towards man.
\end{abstract}

Method. The study population is compulsory and non-compulsory secondary school students aged between 14 and 22 years. The total sample is 874 (430 girls and 444 boys). The questionnaire is made up of 15 behaviors around which one asks if they represent abuse: 14 of which are included as indicators of gender violence in the studies on this topic.

Results. The results show that Spanish adolescents identify abuse behaviors as such (either from boy to girl or girl to boy), with certain exceptions. In a generalized way, girls are more aware of abuse behaviors. Of the 14 behaviors described, in 8 of them there is unanimity by both sexes in considering them mistreatment behaviors, both male to female and female to male. However, they show a tendency to score less seriously those items that refer to abuse behaviors more emotional than physical. Finally, significant differences are obtained according to age, being the people of greater age group those who have a greater perception of the behaviors as mistreatment

Discussion and Conclusions. The set of central results is that both boys and girls value abuse behavior as such, although both sexes value them as such, girls tend to do so with greater severity. What is observed is a tendency in the scores to consider certain behaviors in greater degree when it is the girl who evaluates it. Regarding the fact that the re-knowledge of violence becomes more evident in the older group, different non-exclusive hypotheses can be formulated.

Keywords: Gender violence; Adolescence; Age; Risk factor's; Attitudes and Beliefs. 


\section{Introducción}

La violencia se define como la respuesta aprendida, intencionalmente ejercida para controlar o dañar a los demás (Hernando, 2007). No posee utilidad alguna para el proceso evolutivo natural de selección o adaptación del ser humano. La violencia de pareja ha sido abordada desde diferentes enfoques teóricos, lo que también ha dificultado un consenso sobre su propia definición, encontrándonos con diferentes conceptos para referirnos al fenómeno (Gómez et al., 2000). Desde el marco de la violencia de género, se define como "manifestación de la discriminación, la situación de desigualdad y las relaciones de poder de los hombres sobre las mujeres, se ejerce sobre éstas por parte de quienes sean o hayan sido sus cónyuges, o de quienes estén o hayan estado ligados a ellas por relaciones similares de afectividad, aún sin convivencia" (LO 1/2004). Por otro lado, la literatura sobre el tema también hace referencia a la violencia doméstica y, dentro de ésta, a la conyugal. La principal diferencia entre la violencia de género y la violencia doméstica y conyugal, es que la primera se enmarca en medidas integrales y estructurales frente la violencia por razones de desigualdad de género y, en ese sentido, trabaja con la violencia ejercida del hombre sobre la mujer, en exclusividad (Gómez et al., 2000). Es importante considerar que la violencia en relaciones de pareja puede ser ejercida en todas las edades, grupos sociales y étnicos, independiente de la orientación sexual, estatus económico y lugar de residencia (Hernando, 2007). Otro tipo de referencia es la violencia contra la pareja (VCP). Esta violencia se refiere a la violencia física o sexual, real o amenazante, o al abuso psicológico o emocional por parte de los cónyuges, novios o novias, sean actuales o anteriores. La característica fundamental de este tipo de violencia es la relación sentimental o íntima entre víctima y victimario, al margen del estado civil, orientación sexual o estado de cohabitación (Arias y Robin, 2008). La violencia en el noviazgo se inicia con frecuencia durante la adolescencia y se ha postulado como un factor de riesgo para formas graves de violencia en las parejas adultas; no obstante, el corpus de investigación sobre esta problemática continúa siendo limitado (Rubio-Garay, 2012).

Centrándonos en esta última, cada vez es mayor la aparición de conductas de control en edades tempranas en el seno de las relaciones de noviazgo, haciéndose en el tiempo más extremas y frecuentes (Hernando, 2007). Esto viene alimentado en muchas ocasiones tanto por estereotipos de género como por creencias o mitos errados sobre las relaciones de pareja y el amor romántico. Esto, junto a otros factores, son considerados el "germen" de la violencia machista. Es decir, que este tipo de creencias justifica, en la mayoría de los casos, la violencia ejercida y, por lo tanto, deben erradicarse mediante una educación igualitaria que deslegitime 
roles de dominación masculina y sumisión femenina. Cabe decir que el caso de violencia de género es el resultado de un caso extremo de esta interpretación de roles. No todas las personas que tienen creencias erróneas o toman roles sexistas tienen que ser violentos. Pero se puede afirmar que cuando se ejerce violencia de género sí están presentes, en la inmensa mayoría de los casos, este tipo de creencias y, por tanto, la consecución de los roles asociados a ellas.

La normalización de la violencia de pareja en la adolescencia es mayor si cabe que en otras edades, ya que ellos y ellas son capaces de describir la violencia, conocen casos de violencia de género, pueden identificarla sobre el papel pero, en general, creen que se trata de algo que sólo les ocurre a mujeres mayores que ya están casadas. Además, se da la circunstancia de que determinados comportamientos, que están en la base y en el inicio del problema, como los celos y el control exagerado, para muchos adolescentes son síntomas de amor y preocupación por la pareja y no lo ven como el posible germen del problema. Las razones para disculpar la violencia están presentes en nuestros jóvenes y ellos siguen los mismos mitos y falsas creencias sobre el tema, tal y como corresponde a los roles sociales de la comunidad en la que están insertos (Hernando, 2007).

En una investigación realizada con una muestra de estudiantes de 16 países diferentes (Straus, 2004), se encontraron altos índices de violencia de pareja a nivel mundial. Existen pocos trabajos realizados en España, entre ellos el realizado por González y Santana (2001) que informa que el $7.5 \%$ de los chicos y el $7.1 \%$ de las chicas reconocen que en una o más ocasiones han pegado o empujado a su pareja. La variabilidad de los resultados de las diferentes investigaciones se explica, entre otras razones, por la inexistencia de una definición estándar de dating violence, por lo que las investigaciones sobre la violencia durante el noviazgo utilizan distintas definiciones conceptuales y parámetros para medir la violencia (Hernando, 2007). No obstante, lo que sí parece claro es que la pareja o noviazgo entre adolescentes son un ámbito especial de riesgo de violencia (con independencia del estatus socioeconómico, lugar de residencia, orientación sexual, "raza", etc.). Este tipo de violencia puede tomar muchas formas, incluyendo el abuso emocional, psicológico, físico o sexual, que pueden coexistir, o que puede caracterizarse por uno solo de ellos; la violencia puede ocurrir tanto si ha transcurrido mucho como poco tiempo desde el comienzo de la relación (Hernando, 2007).

Se ha encontrado que es más probable que perpetren actos de violencia hacia sus parejas aquellos que han estado expuestos, en su niñez, a modelos de agresión en las relaciones interparentales; los individuos con actitudes que justifican la violencia, o que mantienen la creencia de que es aceptable la violencia en la resolución de los conflictos interpersonales (Aneshensel, Malik y Sorenson, 1997; O'Keefe, 1997; Byers y Price, 1999); los que presentan 
altos niveles de cólera o los que tienen un bajo nivel de autoestima (O'Keefe, 1997), así como los que tienen actitudes negativas o patriarcales hacia las mujeres.

Los resultados de la investigación Igualdad y Prevención de la Violencia de Género en la Adolescencia, de 2011 (Carvajal y Díaz Aguado, 2011), realizada en el marco de un Convenio entre la Universidad Complutense y el Ministerio de Igualdad, con una muestra de chicos y chicas de entre 14 y 20 años, muestran que los chicos rechazan el sexismo y, sobre todo, la violencia de género de forma mayoritaria, aunque en menor medida que las chicas. Es preciso incrementar los esfuerzos destinados a la prevención, teniendo en cuenta la especial resistencia al cambio que este tema puede suponer para ellos. Otro de los resultados arrojados es que la mentalidad "machista", que subyace tras la violencia de género, destaca como su principal condición de riesgo desde la adolescencia (Hernando y Montilla, 2005). La prevención debe centrarse en dicho problema y evaluar su eficacia en torno a indicadores fiables sobre su superación.

\section{Objetivos e hipótesis}

Lo más relevante, y plantea los objetivos de esta investigación, es que el cambio del modelo patriarcal no está todavía insertado en nuestra sociedad, y esto se ve reflejado en la juventud. De ahí que los esfuerzos por el cambio, entre otros, deban ir encaminados hacia la importancia del papel de la prevención.

El objetivo general de este estudio es identificar aquellas creencias/actitudes en adolescentes españoles (mujeres y hombres) respecto a lo que podrían ser factores de riesgo previos a situaciones de violencia en la pareja. Como objetivos específicos se identifican posibles diferencias en dichas creencias/actitudes de riesgo en adolescentes respecto al género y a la edad.

Se plantean dos hipótesis. La primera es que no hay diferencia entre chicos y chicas a la hora de valorar las conductas de maltrato como graves. La segunda es que el grupo de mayor edad valorará con mayor gravedad las conductas de tanto de abuso emocional como físico.

\section{Método}

\section{Participantes}

La población objeto de estudio ha sido 874 estudiantes de enseñanza secundaria obligatoria y no obligatoria con edades de entre 14 y 22 años, siendo la medía 17, lo que corresponde a estudiantes matriculados en $3^{\circ}$ de la ESO y en cursos posteriores ( $4^{\circ} \mathrm{ESO}$, Bachillerato y otras formaciones). De la muestra total de 874,430 son chicas y 444 son chicos. Los alumnos/as que cursan $3^{\circ}$ de la ESO son 238, los de $4^{\circ}$ ESO 236, de Bachillerato 168 y de otras formaciones 232 alumnos/as. Los estudiantes son alumnos y alumnas de diferentes cen- 
tros de enseñanza pública y privados de las diferentes Comunidades Autónomas de España. El país de origen es España en el caso de 860 estudiantes de la muestra total. Se llevó a cabo una primera estratificación por tipo de estudios y Comunidad Autónoma (C.A.), y, posteriormente, dentro de cada C.A. se estratificaron los centros por titularidad.

\section{Instrumentos}

El cuestionario que se utilizó en el presente estudio ha sido obtenido de la Investigación antes mencionada Igualdad y Prevención de la Violencia de Género en la Adolescencia, de 2011 (fruto del Convenio entre la Universidad Complutense y el Ministerio de Igualdad). Dicho cuestionario consta de 15 conductas diferentes en torno a las cuales se pregunta si representan maltrato o no: 14 de ellas están incluidas como indicadores de la violencia de género en los estudios sobre este tema. Las opciones de respuesta son tipo Likert, donde se tiene que contestar en función de las siguientes clasificaciones: "mucho" (4) "bastante" (3) "poco" (2) y "nada" (1). El cuestionario incluye una conducta que no representa maltrato: "llevarle la contraria en algo" (expresión de la discrepancia necesaria en una relación para mantener la individualidad, que suele ser destacada por maltratadores como justificación).

\section{Procedimiento}

Por un lado, el cuestionario es contestado por chicas (sobre las conductas de los chicos hacia ellas y de ellas hacia ellos) y, por otro lado, por chicos (sobre conductas de las chicas hacia ellos y de ellos hacia ellas), siendo las mismas conductas en ambos casos.

\section{Análisis de datos}

A los cuestionarios aplicados se les calculó la confiabilidad por consistencia interna (coeficiente Alfa de Cronbach 0.95) lo que indica una alta puntuación de estos. El análisis estadístico se realizó mediante la diferencia para medias con una distribución t y un análisis de varianza de una clasificación con el análisis post hoc por el método de Tukey. Con el objetivo de analizar las diferencias obtenidas respecto a la edad, se procedió a realizar un análisis de varianza (ANOVA) para lo cual se dividió a la muestra en 4 grupos de edad: Grupo 1. N=445 (14- 16 años), Grupo 2. N=267 (17-18 años), Grupo 3. N=96 (19-21 años) y Grupo 4. $\mathrm{N}=66(+$ de 22 años $)$. 


\section{Resultados}

Los resultados obtenidos del primer análisis es la percepción de la violencia de género en función del sexo. La tabla 1 muestra los resultados.

Tabla 1. Diferencias por sexo a las respuestas

\begin{tabular}{|c|c|c|c|}
\hline & $\begin{array}{r}\text { CHICAS } \\
\mathrm{N}=430\end{array}$ & $\begin{array}{c}\text { CHICOS } \\
\mathrm{N}=446\end{array}$ & $\mathbf{t}$ \\
\hline & Decirle que no vale nada & Decirle que no vale nada & \\
\hline СНICO А CHICA & $2,12(\mathrm{DT}=0,96)$ & $1,85(\mathrm{DT}=1,11)$ & $3.91 * *$ \\
\hline \multirow[t]{2}{*}{ CHICA A CHICO } & $2,23(\mathrm{DT}=0,95)$ & $2,00(\mathrm{DT}=1,07)$ & $3.48 * *$ \\
\hline & Hacerle sentir miedo & Hacerle sentir miedo & \\
\hline СНICO А СНICA & $2,32(\mathrm{DT}=0,93)$ & $2,11(\mathrm{DT}=1,12)$ & $2,893^{*}$ \\
\hline \multirow[t]{2}{*}{ CHICA A CHICO } & $2,41(\mathrm{DT}=0,90)$ & $2,18(\mathrm{DT}=1,04)$ & $3,386^{* *}$ \\
\hline & Insultarla/le & Insultarla/le & \\
\hline CHICO А CHICA & $2,34(\mathrm{DT}=0,93)$ & $2,11(\mathrm{DT}=1,09)$ & $3,353^{* *}$ \\
\hline \multirow[t]{2}{*}{ CHICA A CHICO } & $2,39(\mathrm{DT}=0,91)$ & $2,20(\mathrm{DT}=1,03)$ & $2,924 *$ \\
\hline & $\begin{array}{l}\text { Decirle con quien puede o no puede } \\
\text { hablar, o a donde puede o no puede ir. }\end{array}$ & $\begin{array}{l}\text { Decirle con quien puede o no puede } \\
\text { hablar, o a donde puede o no puede } \\
\text { ir. }\end{array}$ & \\
\hline CHICO A CHICA & $2,23(\mathrm{DT}=0,94)$ & $1,97(\mathrm{DT}=1,08)$ & $3,737 * *$ \\
\hline \multirow[t]{2}{*}{ CHICA A CHICO } & $2,25(\mathrm{DT}=0,95)$ & $2,09(\mathrm{DT}=1,04)$ & $2,487 *$ \\
\hline & Tratar de que no vea a sus amigas/os & $\begin{array}{l}\text { Tratar de que no vea a sus ami- } \\
\text { gas/os }\end{array}$ & \\
\hline CHICO A CHICA & $2,26(\mathrm{DT}=0,94)$ & $2,03(\mathrm{DT}=1,10)$ & $3,353 * *$ \\
\hline \multirow{2}{*}{ CHICA A CHICO } & $2,30(\mathrm{DT}=0,91)$ & $2,13(\mathrm{DT}=1,03)$ & $2,652 *$ \\
\hline & Controlar todo lo que hace & Controlar todo lo que hace & \\
\hline CHICO A CHICA & $2,09(\mathrm{DT}=0,92)$ & $1,87(\mathrm{DT}=1,03)$ & $3,319^{* *}$ \\
\hline \multirow{2}{*}{ CHICA A CHICO } & $2,08(\mathrm{DT}=0,96)$ & $1,93(\mathrm{DT}=1,07)$ & $2,215^{*}$ \\
\hline & $\begin{array}{l}\text { Insistir en tener una relación sexual } \\
\text { cuando ella/él no quiere }\end{array}$ & $\begin{array}{l}\text { Insistir en tener una relación sexual } \\
\text { cuando ella/él no quiere }\end{array}$ & \\
\hline CHICO A CHICA & $2,44(\mathrm{DT}=0,86)$ & $2,08(\mathrm{DT}=1,06)$ & $5,530^{* *}$ \\
\hline \multirow[t]{2}{*}{ CHICA A CHICO } & $2,39(\mathrm{DT}=0,90)$ & $1,98(\mathrm{DT}=1,12)$ & $5,911 * *$ \\
\hline & Decirle que si le deja le hará daño & Decirle que si le deja le hará daño & \\
\hline CHICO A CHICA & $2,30(\mathrm{DT}=1,00)$ & $2,13(\mathrm{DT}=1,15)$ & $2,253^{*}$ \\
\hline \multirow[t]{2}{*}{ CHICA A CHICO } & $2,33(\mathrm{DT}=0,95)$ & $2,13(\mathrm{DT}=1,11)$ & $2,956^{*}$ \\
\hline & Pegarle/a & Pegarle/a & \\
\hline CHICO А CHICA & $2,69(\mathrm{DT}=0,85)$ & $2,50(\mathrm{DT}=1,04)$ & $2,954 *$ \\
\hline \multirow[t]{2}{*}{ CHICA A CHICO } & $2,63(\mathrm{DT}=0,80)$ & $2,45(\mathrm{DT}=1,02)$ & 2,990 * \\
\hline & $\begin{array}{l}\text { Obligarle a hacer cosas que no quiere con } \\
\text { amenazas }\end{array}$ & $\begin{array}{l}\text { Obligarle a hacer cosas que no } \\
\text { quiere con amenazas }\end{array}$ & \\
\hline CHICO А CHICA & $2,58(\mathrm{DT}=0,82)$ & $2,31(\mathrm{DT}=1,03)$ & $4,313^{* *}$ \\
\hline \multirow[t]{2}{*}{ CHICA A CHICO } & $2,54(\mathrm{DT}=0,82)$ & $2,29(\mathrm{DT}=1,04)$ & $3,893 * *$ \\
\hline & $\begin{array}{l}\text { Grabarla/le en móvil o en vídeo, o hacerle } \\
\text { fotos sin que ella/él lo sepa }\end{array}$ & $\begin{array}{l}\text { Grabarla/le en móvil o en vídeo, o } \\
\text { hacerle fotos sin que ella/él lo sepa }\end{array}$ & \\
\hline CHICO A CHICA & $2,32(\mathrm{DT}=0,92)$ & $2,05(\mathrm{DT}=1,05)$ & $3,999 * *$ \\
\hline \multirow[t]{2}{*}{ CHICA A CHICO } & $2,40(\mathrm{DT}=0,88)$ & $2,18(\mathrm{DT}=1,02)$ & $3,437 * *$ \\
\hline & $\begin{array}{l}\text { Enviarle mensajes por Internet o teléfono } \\
\text { móvil, asustando, ofendiendo o amena- } \\
\text { zando }\end{array}$ & $\begin{array}{l}\text { Enviarle mensajes por Internet o } \\
\text { teléfono móvil, asustando, ofen- } \\
\text { diendo o amenazando }\end{array}$ & \\
\hline CHICO А CHICA & $2,59(\mathrm{DT}=0,82)$ & $2,33(\mathrm{DT}=1,07)$ & $3,888^{* *}$ \\
\hline \multirow[t]{2}{*}{ CHICA A CHICO } & $2,55(\mathrm{DT}=0,82)$ & $2,34(\mathrm{DT}=1,01)$ & $3,469 * *$ \\
\hline & $\begin{array}{l}\text { Difundir mensajes, insultos o imágenes } \\
\text { suyas sin que ella hubiera dado permiso }\end{array}$ & $\begin{array}{l}\text { Difundir mensajes, insultos } \quad \text { o } \\
\text { imágenes suyas sin que ella hubiera } \\
\text { dado permiso }\end{array}$ & \\
\hline СНICO А СНICA & $2,57(\mathrm{DT}=0,84)$ & $2,31(\mathrm{DT}=1,07)$ & $3,874 * *$ \\
\hline CHICA A CHICO & $2,53(\mathrm{DT}=0,85)$ & $2,32(\mathrm{DT}=0,41)$ & $3,233 * *$ \\
\hline
\end{tabular}

$* p<, 05 ; * * p<, 01$ 
Como puede verse, los valores de la mayoría de los ítems cuentan con diferencias significativas respecto a si quien evalúa las conductas es un chico o una chica, excepto dos ítems ("Llevarle la contraria en algo" y "Romperle algo") en los que no existen diferencias. La tendencia es que el grado de conciencia de maltrato es mayor entre las chicas. Sin embargo, muestran una tendencia a puntuar con menor gravedad las conductas que pertenecen a aspectos más de abuso emocional, donde puede reflejarse en los siguientes ítems "Controlar todo lo que hace", "Decirle que no vale nada" y "Tratar que no vea a sus amigos/as". Los datos del análisis de varianza se muestran en las tablas 2 y 3 . Las tablas 2 y 3 muestran que las mayores diferencias se obtienen entre el grupo de 14 a 16 años comparado con el de mayor de 22 años.

Tabla 2. Comparación respecto a las respuestas en función del Grupo de Edad en la Muestra Total (de chico a chica)

\begin{tabular}{|c|c|c|c|c|c|c|}
\hline & $\begin{array}{l}\text { Grupo } 1 \\
14-16 \text { años } \\
X \text { (D.T) }\end{array}$ & $\begin{array}{l}\text { Grupo } 2 \\
17-18 \text { años } \\
X(D . T)\end{array}$ & $\begin{array}{l}\text { Grupo } 3 \\
19-21 \text { años } \\
X \text { (D.T) }\end{array}$ & $\begin{array}{l}\text { Grupo } 4 \\
>22 \text { años } \\
\text { X (D.T) }\end{array}$ & $\mathbf{F}$ & Tukey \\
\hline Hacerle sentir miedo & $2,17(1,05)$ & $2,17(1,07)$ & $2,26(0,98)$ & $2,58(0,78)$ & $3,134^{*}$ & $1 / 4,2 / 4$ \\
\hline $\begin{array}{l}\text { Decirle con quien puede o } \\
\text { no puede hablar, o a } \\
\text { donde puede o no puede } \\
\text { ir. }\end{array}$ & $2,06(1,05)$ & $2,04(1,02)$ & $2,19(0,95)$ & $2,45(0,86)$ & $3,491^{*}$ & $1 / 4,2 / 4$ \\
\hline $\begin{array}{l}\text { Controlar todo lo que } \\
\text { hace }\end{array}$ & $1,89(1,02)$ & $1,99(0,97)$ & $2,10(0,92)$ & $2,35(0,83)$ & $4,844 * *$ & $1 / 4,2 / 4$ \\
\hline $\begin{array}{l}\text { Insistir en tener una rela- } \\
\text { ción sexual cuando ella } \\
\text { no quiere }\end{array}$ & $2,19(1,02)$ & $2,24(0,99)$ & $2,41(0,87)$ & $2,52(0,82)$ & $2,922 *$ & $1 / 4$ \\
\hline $\begin{array}{l}\text { Decirle que si le deja le } \\
\text { hará daño }\end{array}$ & $2,17(1,11)$ & $2,14(1,12)$ & $2,36(0,96)$ & $2,58(0,82)$ & $3,705^{*}$ & $1 / 4,2 / 4$ \\
\hline Pegarla & $2,54(0,98)$ & $2,57(0,96)$ & $2,74(0,78)$ & $2,83(0,64)$ & $2,749^{*}$ & $1 / 4$ \\
\hline $\begin{array}{l}\text { Obligarle a hacer cosas } \\
\text { que no quiere con amena- } \\
\text { zas }\end{array}$ & $2,38(0,96)$ & $2,43(0,98)$ & $2,60(0,82)$ & $2,70(0,78)$ & $3,172 *$ & $1 / 4$ \\
\hline
\end{tabular}


Tabla 3. Comparación respecto a las respuestas en función del Grupo de Edad en la Muestra Total (de chica a chico)

\begin{tabular}{|c|c|c|c|c|c|c|}
\hline & $\begin{array}{l}\text { Grupo } 1 \\
14-16 \text { años } \\
\text { X (D.T) }\end{array}$ & $\begin{array}{l}\text { Grupo } 2 \\
17-18 \text { años } \\
X(D . T)\end{array}$ & $\begin{array}{l}\text { Grupo } 3 \\
19-21 \text { años } \\
\text { X (D.T) }\end{array}$ & $\begin{array}{l}\text { Grupo } 4 \\
>22 \text { años } \\
\text { X (D.T) }\end{array}$ & $\mathbf{F}$ & Tukey \\
\hline Decirle que no vale nada & $2,04(1,02)$ & $2,12(1,05)$ & $2,26(0,97)$ & $2,39(0,89)$ & $3,140^{*}$ & $1 / 4$ \\
\hline Hacerle sentir miedo & $2,26(0,98)$ & $2,25(1,03)$ & $2,36(0,90)$ & $2,59(0,80)$ & $2,534^{*}$ & $1 / 4,2 / 4$ \\
\hline $\begin{array}{l}\text { Tratar de que no vea a sus } \\
\text { amigos }\end{array}$ & $2,14(1,01)$ & $2,21(0,98)$ & $2,34(0,81)$ & $2,52(0,84)$ & $8,078^{* *}$ & $1 / 4$ \\
\hline Grabarle sin que lo sepa & $2,22(0,99)$ & $2,26(0,96)$ & $2,55(0,79)$ & $2,47(0,91)$ & $3,909 * *$ & $1 / 4,2 / 3$ \\
\hline $\begin{array}{l}\text { Insistir en tener una rela- } \\
\text { ción sexual cuando él no } \\
\text { quiere }\end{array}$ & $2,08(1,09)$ & $2,22(1,01)$ & $2,34(0,91)$ & $2,44(0,91)$ & $3,785^{* *}$ & $1 / 4$ \\
\hline Pegarle & $2,48(0,96)$ & $2,52(0,94)$ & $2,72(0,73)$ & $2,77(0,74)$ & $3,219^{*}$ & $1 / 4$ \\
\hline $\begin{array}{l}\text { Obligarle a hacer cosas } \\
\text { que no quiere con amena- } \\
\text { zas }\end{array}$ & $2,35(0,97)$ & $2,39(0,97)$ & $2,68(0,73)$ & $2,59(0,89)$ & $3,936^{* *}$ & $1 / 3,2 / 3$ \\
\hline $\begin{array}{l}\text { Enviarle mensajes por } \\
\text { Internet o teléfono móvil, } \\
\text { asustando, ofendiendo o } \\
\text { amenazando }\end{array}$ & $2,39(0,96)$ & $2,40(0,95)$ & $2,70(0,72)$ & $2,62(0,85)$ & $3,926^{* *}$ & $1 / 3,2 / 3$ \\
\hline $\begin{array}{l}\text { Difundir mensajes, insul- } \\
\text { tos o imágenes suyas sin } \\
\text { que él hubiera dado per- } \\
\text { miso }\end{array}$ & $2,35(0,98)$ & $2,39(0,96)$ & $2,70(0,74)$ & $2,65(0,86)$ & $4,903 * *$ & $1 / 3,1 / 4,2 / 3$ \\
\hline
\end{tabular}

De todas las diferencias encontradas, las que conviene destacar son "controlar todo lo que hace" "Decir que si le deja le hará daño" (cuando es de chico a chica) y "Tratar que no vea a sus amigos" "Difundir mensajes, insultos o imágenes suyas sin que él hubiera dado permiso" (cuando es de chica a chico). Estos ítems son los de mayor relevancia en la percepción de la violencia explícita.

\section{Discusión y conclusiones}

El conjunto de resultados centrales es que tanto chicos como chicas valoran las conductas de maltrato como tal (tanto si es de chico a chica como al revés), siendo las conductas que tienen que ver con aspectos físicos más altamente valoradas en gravedad que las que tie- 
nen que ver con aspectos emocionales. Aunque ambos sexos las valoran como tal, las chicas tienden a hacerlo con una mayor severidad.

Sin embargo, coinciden en las que no lo son, como "Llevar la contraria en algo" se considera por la mayoría una conducta normalizada que implica que la persona busque su individualidad; en este caso, si se considera como maltrato puede indicar más bien deseo de sumisión o que, para que la relación de pareja vaya bien, tiene que inhibirse la discrepancia (aunque bajo, un porcentaje considerable de adolescentes piensan así).

La tendencia a valorar las conductas referentes a los aspectos emocionales como menos graves se debe a la dificultad mayor de ser detectadas y conceptualizadas. La problemática en cuanto a la violencia psicológica en las relaciones de pareja de adolescentes se complica cuando no es identificada por quien la recibe y quien la ejerce. La dificultad para etiquetar la violencia es un factor de riesgo importante (Rodríguez, 2015).

Lo que sí se observa es una tendencia en las puntuaciones a considerar en mayor grado ciertas conductas cuando es la chica la que lo evalúa. Las actitudes sexistas diferencian entre niños y niñas en edades muy tempranas, por lo que, ya en la escuela secundaria, los niños muestran actitudes más negativas hacia las mujeres que hacia las niñas (Ferragut, Blanca y Ortiz-Tallo, 2013). Una explicación puede deberse a una mayor concienciación respecto a la violencia en la pareja por parte de las chicas o, a la inversa, la menor conciencia por parte de los chicos y la necesidad de enfocar más la prevención en este colectivo. Sin embargo, una de las problemáticas en la VN (Violencia en el Noviazgo) radica en no ser percibida como tal por la población víctima. Un estudio realizado por Antuña, Bringas, Franco, López-Cepero y Rodríguez (2012), encontró que comportamientos asociados a la violencia de noviazgo no necesariamente son considerados como abusivos por parte de mujeres adolescentes, por lo que se les puede restar gravedad y no reportarlos. En el caso de los adolescentes, la intervención debería ir encaminada a eliminar ideas erróneas subyacentes al fenómeno de la violencia de género/violencia entre la pareja. Por otro lado, se tendría que capacitar a los adolescentes para detectar y reconocer el maltrato físico, psicológico y sexual, haciendo hincapié en el de tipo psicológico y sexual, ya que son considerados o percibidos como menos graves.

Respecto a que el reconocimiento de la violencia se haga más manifiesto en el grupo de mayor edad se pueden formular diferentes hipótesis no excluyentes. La primera, eminentemente madurativa, consiste en que aproximadamente a partir de los 19 años en adelante ya se ha completado el proceso de desarrollo de las áreas prefrontales del cerebro y se puede, por 
lo tanto, hacer inferencias sobre las consecuencias de las conductas propias y ajenas a largo plazo (Álvarez, 2015). La segunda es que el concepto del amor, de las relaciones sexuales y amorosas cambia a lo largo de los años. Esto viene alimentado, en muchas ocasiones, tanto por estereotipos de género como por creencias o mitos errados sobre las relaciones de pareja y el amor romántico (Hernando, 2007). El grupo de más de 22 años, en general, considera con mayor gravedad las conductas expuestas, tanto cuando las conductas son de chico a chica, como de chica a chico. La mayoría de las conductas donde existen diferencias entre grupos de edades son las de índole psicológico, pero llama la atención que en el ítem "Pegarle" haya diferencias entre edades, siendo una conducta de violencia física muy clara. Finalmente, una tercera hipótesis es que una diferencia de 5 años o más entre los grupos pueda revelar cambios en los patrones culturales en ese periodo y se esté, por lo tanto, recogiendo tanta información de los sujetos, como el reflejo de la cultura actual de la primera adolescencia.

Una teoría explicativa de la VN (Violencia en el Noviazgo) es la del modelo ecológico, el cual asume una perspectiva interaccionista para explicar este hecho. De esta manera, el modelo plantea que la interacción de todos estos sistemas y factores aumentan o disminuyen el riesgo de violencia de pareja en el adolescente, por lo que la intervención debe estar enfocada en los sistemas y no solo en el individuo (Monreal-Gimeno, Povedano-Díaz y MartínezFerrer, 2014). Las líneas de intervención deberían centrarse en actuar en los primeros años de escolarización, basándose en un sistema educativo de igualdad de derechos entre sexos.

\section{Referencias}

Alberdi, I. y Rojas, L. (2005). Violencia: intolerancia cero. Barcelona: Fundación "La Caixa".

Álvarez, M. A. (2015) Datos blandos para ciencias duras. Madrid: EOS.

Arias, I., y Robin, M. I. (2008). Etiología y vigilancia de la violencia de pareja. En J.R. Lutzker (eds.), Prevención de violencia. Investigación y estrategias de intervención basadas en la evidencia (165-184). México: El Manual Moderno.

Díaz-Aguado, M. J. y Carvajal, M. I. (2011). Igualdad y prevención de la violencia de género en la adolescencia. Madrid: Ministerio de Igualdad, Delegación del Gobierno para la Violencia de Género.

Echeburúa, E. y Guerricaechevarría, C. (2005). Abuso sexual en la infancia: víctimas y agresores. Barcelona: Ariel.

Franco, L., Antuña, M., López-Cepero, J., Rodríguez, F. y Bringas, C. (2012). Tolerancetowardviolence in spanishadolescents. Psicothema. 236-242.

- 714 - $\quad$ Electronic Journal of Research in Educational Psychology, 16(3), 703 - 715. ISSN: 1696-2095. 2018. no. 46 
Gómez, R.; Muñoz, V.; Vázquez, B.; Gómez, R. y Mateos, N. (2000). Guía de buenas prácticas para la evaluación psicológica forense del riesgo de violencia contra la mujer en las relaciones de pareja (VCMP). Madrid: Colegio Oficial de Psicólogos de Madrid.

González, R. y Santana, JD. (2001). La violencia en parejas jóvenes. Psicothema, 13(1), 127131.

Hernando, Á. (2007). La prevención de la violencia de género en adolescentes. Una experiencia en el ámbito educativo. Apuntes de Psicología, 25(3), 325-340.

Hernando, A. y Montilla, C. (2005). El Orientador como profesional educativo en los Centros de Enseñanza Secundaria. En J. M. Coronel y S. González (Coord.), El trabajo psicopedagógico en los Centros de Enseñanza Secundaria (147-162). Málaga: Aljibe.

Ley Orgánica 1/2004, de 28 de diciembre, de Medidas de Protección Integral sobre la Violencia de Género [Internet]. Disponible en http://www.boe.es/boe/dias/2004/12/29/pdfs/A42166-42197.pdf

Malik, S.; Sorenson, S. B. y Aneshensel, C.S. (1997). Community and dating violence among adolescents: perpetration and victimization. Journal of Adolescent Health 21(5), 291302.

Monreal-Gimeno, M.C, Povedano-Díaz, A. y Martínez-Ferrer, B. (2014). Modelo ecológico de los factores asociados a la violencia de género en parejas adolescentes. Journal for Educators, Teachers and Trainers, Vol. 5(3), pp. 105 - 114.

O’Keefe, M. (1997). Predictor of dating violence among high school students. Journal of Interpersonal Violence, 12(4), 546-568.

Price, E.L. y Byers, S.E. (1999). The attitudes towards dating violence scales: development and initial validation. Journal of Family Violence, 14(4), 351-375.

Rodríguez, S. (2015). Violencia en parejas jóvenes: estudio preliminar sobre su prevalencia y sus motivos. Pedagogía Social. Revista Interuniversitaria, 25, 251- 275. doi: 10.7179/PSRI_2015.25.11

Rubio-Garay, F., López-González, M. A., Saúl L. A., Sánchez-Elvira, A. (2012). Direccionalidad y expresión de la violencia en las relaciones de noviazgo de los jóvenes. Acción psicológica, 9(1), 61-70.

Ferragut, M., Blanca, M. J., y Ortiz-Tallo, M. (2013). Psychological values as protective factors against sexist attitudes in preadolescents. Psicothema 2013. Vol. 25, $n^{\circ} 1$, pp. 3842.

Straus, M. A. (2004). Prevalence of violence against dating partners by male and female university students worldwide. Violence against women, 10(7), 790-811. 